\title{
Comparative Evaluation of Antibacterial Activity of Silver Nanoparticles Biosynthesized Using Fruit Juices
}

\author{
Basavaraj S Hungund ${ }^{1 *}$, Gayatri R Dhulappanavar ${ }^{1}$ and Narasimha H Ayachit ${ }^{2}$ \\ ${ }^{1}$ Department of Biotechnology, BVB College of Engineering and Technology, Hubballi, Karnataka 580031, India \\ ${ }^{2}$ Department of Physics, Rani Channamma University, Belagavi, Karnataka 591156, India
}

\begin{abstract}
Synthesis of nanosized particles with antimicrobial property is of significance in therapeutic applications of nanotechnology. The present study reports an environmental friendly and rapid method for biosynthesis of silver nanoparticles and their antibacterial activity. This green synthetic method used various fruit juices like sweet lime, lime and orange as a reducing and capping agent for silver nitrate. Different thermal reduction methods-microwave oven and hot plate were used for synthesizing silver nanoparticles. The silver ions were reduced into silver nanoparticles within few minutes of reaction. Silver nanoparticles so prepared were characterized using UV-visible spectrophotometer and scanning electron microscope. An effort was also been made to predict the size of the silver nanoparticles using UV-visible spectra by Mie Scattering protocol. Scanning electron micrograph (SEM) revealed useful information about the morphology of silver nanoparticles. The synthesized silver nanoparticles showed antibacterial property against pathogenic bacteria Escherichia coli, Salmonella typhimurium, Klebsiella pneumoniae and Staphylococcus aureus. Agar well diffusion method was adopted to assay the nanoparticles for bactericidal activity against test organisms on nutrient agar plates. Silver nanoparticles biosynthesized from orange fruit juice were more effective as antibacterial agent. The maximum zones of inhibition of $8.0 \mathrm{~mm}, 6.0 \mathrm{~mm}, 8.0 \mathrm{~mm}$ and $5.0 \mathrm{~mm}$ were observed against Escherichia coli, Salmonella typhi, Klebsiella pneumoniae and Staphylococcus aureus respectively. The study shows that gram negative bacteria are more susceptible to antibacterial action of silver nanoparticles. Such studies are crucial in the demonstration of therapeutic importance of silver nanoparticles.
\end{abstract}

Keywords: Fruit juice; Biosynthesis; Silver nanoparticles; Characterization; Antibacterial effect

\section{Introduction}

The development of reliable green processes for the synthesis of silver nanoparticles is an important aspect of current nanotechnology research. Noble metal nanoparticles have been the subject of focus due to their unique optical, electronic, mechanical, magnetic and chemical properties. Preparation of silver nanoparticles has attracted particularly considerable attention due to their diverse properties and uses like magnetic and optical polarizability, catalysis [1], electrical conductivity [2] antimicrobial activities [3-5], DNA sequencing [6] and surface-enhanced Raman scattering [7]. Nanomaterials such as Ag, $\mathrm{Au}, \mathrm{Pt}$, and $\mathrm{Pd}$ have been synthesized by different methods, including hard template [8], using bacteria [9], fungi [10] and plants [11]. The strong toxicity of silver nanoparticles have been recently shown to be promising antimicrobial material. Sondi et al. studied the antimicrobial activity of silver nanoparticles against Escherichia coli as a model of Gram-negative bacteria [12]. The health benefits provided by fruits and vegetables can be attributed to many biologically active phytochemicals present. These biological activities include functions like detoxification, immuno-protection, antiviral, anticancer and antioxidant properties [13]. Employing nano-biotechnological protocols have observed an increase in the area of synthesis of nanomaterials employing microbes, plants/plant parts and conglomerate of nutrients/biochemicals like honey. A quest for an environmentally sustainable synthesis process has led to a few biomimetic approaches. Sometimes the synthesis of nanoparticles using plants or parts of plants can prove advantageous over other biological processes by eliminating the elaborate processes of culturing of microorganisms. Among metal nanoparticles, silver nanoparticles (AgNPs) have been known to have inhibitory and antimicrobial activity. Considering the antioxidant properties of fruit juices, we have made an attempt to use fruit juice as conglomerate of metabolites as reducing and stabilizing agent for the biosynthesis of metal nanoparticles.

\section{Materials and Methods}

\section{Materials}

Silver nitrate procured from Merck was used as a base and fruit juices as reducing and stabilizing agent. Double distilled water was used for all of the preparations. Good quality fruits- orange, lime and sweet-lime were procured from local market, washed, mechanically pressed and stored in pre-sterilized glass bottles. Bacterial cultures used for studying antibacterial activity were procured from National Collection of Industrial Microorganisms (NCIM), NCL Pune.

\section{Biosynthesis of silver nanoparticles}

The synthesis of AgNPs was carried out using silver nitrate base ( $1 \mathrm{mM}$ and $10 \mathrm{mM}$ ) along with the fruit juices. The experiments were carried out by means of thermal reduction (microwave radiation and hot plate). Fruit juice as collected above was centrifuged at 5000 $\mathrm{rpm}$ for five minutes. The pellet was discarded and supernatant was collected. The experiments were carried out by means of thermal reduction process (microwave irradiation and hot plate methods). For the biosynthesis of AgNPs using microwave method, silver nitrate base $(1 \mathrm{mM}$ and $10 \mathrm{mM})$ and fruit juice were mixed at a proportion of $1: 1$,

*Corresponding author: Basavaraj S. Hungund, Department of Biotechnology BVB College of Engineering and Technology, Vidyanagar, Hubli-580031, Karnataka, India, Tel: 91-9449169349; Fax: 91-836-2374985; E-mail: hungundb@gmail.com

Received December 09, 2014; Accepted February 11, 2015; Published February 22, 2015

Citation: Hungund BS, Dhulappanavar GR, Ayachit NH (2015) Comparative Evaluation of Antibacterial Activity of Silver Nanoparticles Biosynthesized Using Fruit Juices. J Nanomed Nanotechnol 6: 271. doi:10.4172/2157-7439.1000271

Copyright: (c) 2015 Hungund BS, et al. This is an open-access article distributed under the terms of the Creative Commons Attribution License, which permits unrestricted use, distribution, and reproduction in any medium, provided the original author and source are credited. 
2:1, 3:1, 4:1. The contents were taken in a Teflon container and placed in microwave oven for three minutes at medium heat setting. The color change from colorless to brown was observed. Similar microwave irradiation was carried out in a glass container. The color change was observed from colorless to brown for $1 \mathrm{mM}$ and colorless to dark brown for $10 \mathrm{mM}$. Similarly for hot plate method, silver nitrate base $(1 \mathrm{mM}$ and $10 \mathrm{mM})$ and lemon juice were mixed in a conical flask at the ratio of 4:1 and 2:1. The conical flask was kept on a hotplate and heated at about $80^{\circ} \mathrm{C}$ for $10-15$ minutes. Color change was observed from colorless to yellow for $1 \mathrm{mM}$ and colorless to dark brown for 10 $\mathrm{mM}$. Same process was applied for all the three juices (orange, sweet lime and lime).

\section{Characterization by UV-Vis spectroscopy}

Nanoparticles are made directly as powders and must be stored in a liquid medium for suspension. If the nanoparticles are aggregated, they will build a solid bridge causing them to lose their nanoparticle properties. All the samples are prepared and stored in double distilled water. The silver nanoparticles were characterized by UV-Vis Spectroscopy, one of the most widely used techniques for structural characterization of silver nanoparticles [14]. Aliquots of solutions of different concentrations ( $25 \%$ and $50 \%$ ) were ultrasonicated to disperse particles and were measured using UV-Vis spectrophotometer (Double beam, Make: Labomed, USA). An aliquot of the sample was also used for scanning electron microscopic studies, $25 \mu \mathrm{l}$ of sample was sputter coated on copper stub and the images of nanoparticles were studied using SEM.

\section{Characterization by SEM}

The synthesized silver nanoparticles were characterized using scanning electron microscope. Usually scanning electron microscope is used to characterize the internal properties like exact size, shape, dimensions of nanoparticles. A thin layer of AgNPs solution was placed on sample holder (silica piece). The care was taken that bubbles should not be present. Next the sample holder was kept in the dessicator for half an hour. Further the sample holder containing dry sample was exposed to gold sputtering. This is done to maintain the electron channeling. When sample containing silica piece is mounted into the SEM equipment, the electron beam was made to fall on sample for characterization. If the beam is of high intensity then flow of electron can be controlled by electron channeling. Hence gold sputtering was carried out. Different images were obtained which confirmed the presence of AgNPs.

\section{Characterization by scanning tunneling microscope}

The synthesized silver nanoparticles were characterized using scanning tunneling microscope (Nano Surf Easy Scan 2). Usually scanning tunneling microscope (STM) is used to characterize the superficial properties of nanoparticles. A thin layer of AgNPs solution was placed on sample holder. The care was taken that bubbles should not be present. Next the sample holder was kept in the dessicator for two hours. Further the sample holder containing dry sample was used for characterization using STM. Different images were obtained which confirmed the presence of SNPs.

\section{Evaluation of antibacterial activity}

Silver nanoparticles biosynthesized from lemon juice, orange juice and sweet lime juice were tested individually against test organisms for antibacterial activity by agar well diffusion method [15]. For this study both Gram positive (Staphylococcus aureus ATCC 6538P) and
Gram negative (Escherichia coli ATCC 8739, Salmonella typhimurium ATCC 23564 and Klebsiella pneumonia ATCC 10031) organisms were used. This was performed by determining ZoI (zone of inhibition), which is rapid and inexpensive to determine the susceptibility of a particular test organism to antimicrobial agent. This was executed by measuring the zone of inhibition using a vernier caliper. Pure cultures were subcultured into nutrient broth and incubated at $37^{\circ} \mathrm{C}$ for 24 48 hours. Three wells of $5 \mathrm{~mm}$ diameter were made on pre-incubated nutrient agar plates using gel puncture. Each test organism $\left(10^{6} \mathrm{cfu} /\right.$ $\mathrm{mL}$ ) was spread uniformly onto the individual plates using spread plate technique. Using sterile micropipette tips, $0.1 \mathrm{~mL}(100 \mu \mathrm{L})$ of the sample of silver nanoparticle solution was pipette into each of the wells in all the plates. After incubation, the diameters of zone of inhibition were measured in triplicate.

\section{Results and Discussion}

\section{Biosynthesis of silver nanoparticles}

It is well known that silver nanoparticles exhibit a yellowishbrown color in aqueous solution due to excitation of surface plasmon vibrations of silver nanoparticles [16]. Reduction of silver ions to silver nanoparticles could be followed by a color change and UV-Vis spectra. The technique outlined above has proven to be very useful for the analysis of nanoparticles [17]. Therefore, the progress in conversion reaction of silver ions to silver nanoparticles was followed by a color change and spectroscopic techniques. The photograph of sample solutions containing silver nitrate and silver nitrate in the presence of optimal amounts of fruit juices after completion of the reaction shows appearance of a yellowish-brown color which confirms the existence of silver nanoparticles (photo not shown). Several approaches have been employed to obtain better synthesis of silver nanoparticles. Recently, synthesis of silver nanoparticles using plant extracts getting more attraction $[18,19]$. Citrus fruits like orange and lemon are rich source of antioxidants. The compounds present in these fruit juices possess a broad spectrum of chemical and biological activities including radical scavenging properties [20]. Flavonoids present have been reported to exhibit antioxidant, anti-carcinogenic, antihypertensive and antimicrobial properties. The orange juice contains oxido-reductively labile ascorbic acid and citric acid. These two compounds along with polyphenols might have played a pivotal role in nano-conversion. In a recent study, the function of citrate ions in the synthesis of silver nanoplates through a synergetic reduction approach in ambient conditions was explored and it was found that the citrate ions can play multiple roles in the synthesis process including a reducing agent, a stabilizer, and a complex agent and they show some unique features under the reported conditions [21]. The silver nanoparticles were characterized by UV-Vis spectroscopy. The absorption spectra (Figures 1-3) of silver nanoparticle solution prepared with the proposed method showed a surface plasmon absorption band with a maximum of 420$430 \mathrm{~nm}$, indicating the presence of spherical Ag nanoparticles. These structural details were confirmed by SEM images. Scanning electron microscopy provided further insight into the morphology and size details of the silver nanoparticles. Comparison of experimental results showed that the diameter of prepared nanoparticles in the solution was about 45-50 nm. Figures 4-6 show scanning tunneling microscopic images of silver nanoparticles biosynthesized from lime juice, sweet lime juice and orange juice respectively. Similarly Figures 7-9 shows the scanning electron micrograph of silver nanoparticles obtained from orange juice, lime juice and sweet lime juice respectively. Chemical synthesis methods may lead to the presence of some toxic chemical species adsorbed on the surface that may have adverse effects in its 
Citation: Hungund BS, Dhulappanavar GR, Ayachit NH (2015) Comparative Evaluation of Antibacterial Activity of Silver Nanoparticles Biosynthesized Using Fruit Juices. J Nanomed Nanotechnol 6: 271. doi:10.4172/2157-7439.1000271

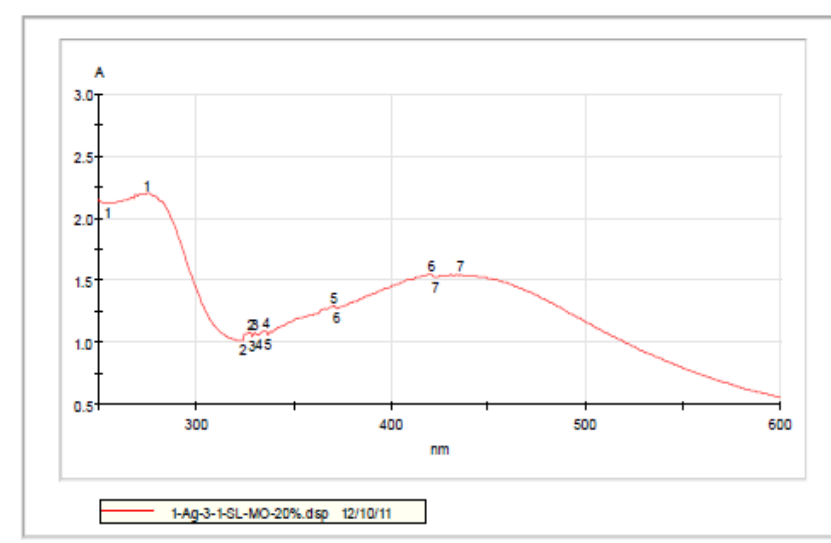

Figure 1: UV-Vis absorption spectrum of silver nanoparticles biosynthesized from lime juice.

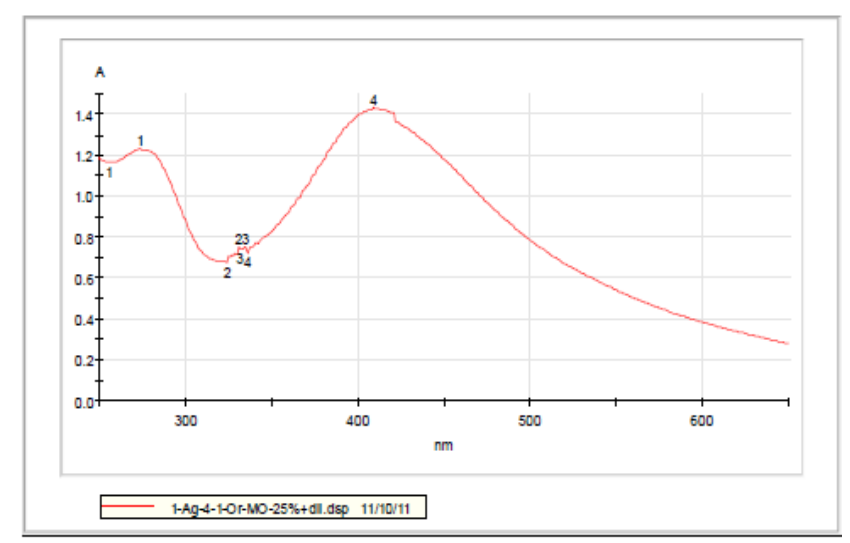

Figure 2: UV-Vis absorption spectrum of silver nanoparticles biosynthesized from orange juice.

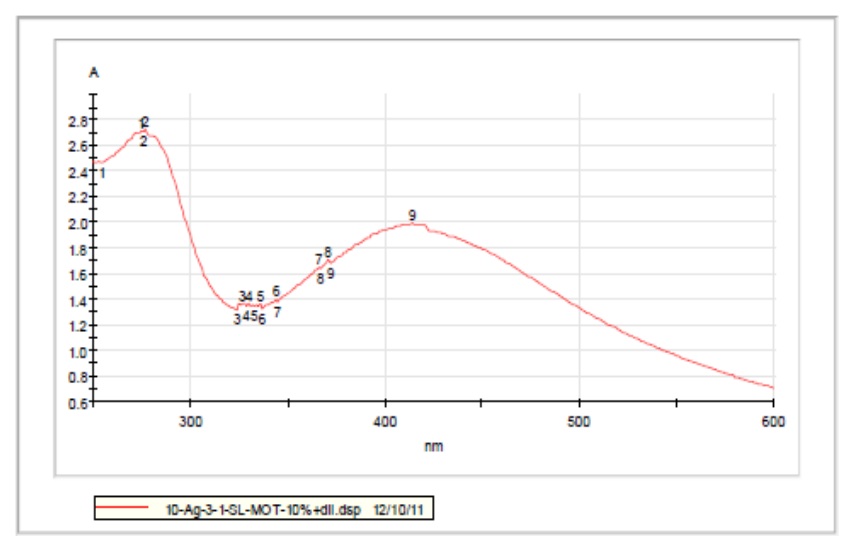

Figure 3: UV-Vis absorption spectrum of silver nanoparticles biosynthesized from sweet-lime juice.

applications [22]. The possible chemical residues on nanoparticles may interact with biological systems. The biological approach of synthesis of nanoparticles can potentially eliminate this problem by making the nanoparticles more biocompatible.

\section{Bactericidal activity of silver nanoparticles}

After 24 hours of incubation, the inhibitory effect of AgNPs from orange juice was significant as compared to the other two. Zone of inhibition (ZoI) was used as a measure for comparing bactericidal activity of these AgNPs. AgNPs from orange showed about $8 \mathrm{~mm}$ zone against the test organisms: E. coli and K. pneumoniae. Similarly the AgNPs from orange showed $5 \mathrm{~mm}$ and $6 \mathrm{~mm}$ ZoI against test
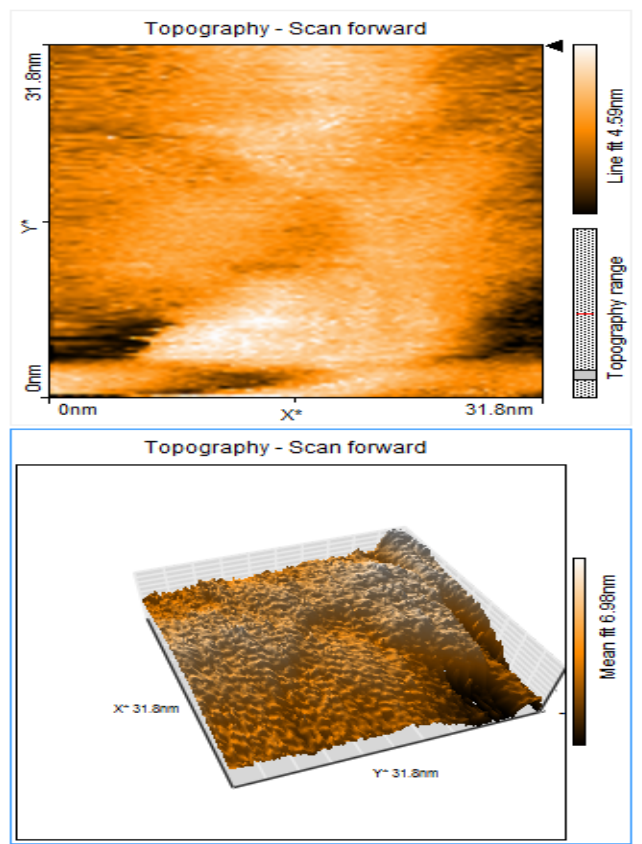

Figure 4: Scanning Tunneling Microscopic image of silver nanoparticles biosynthesized from lime juice.

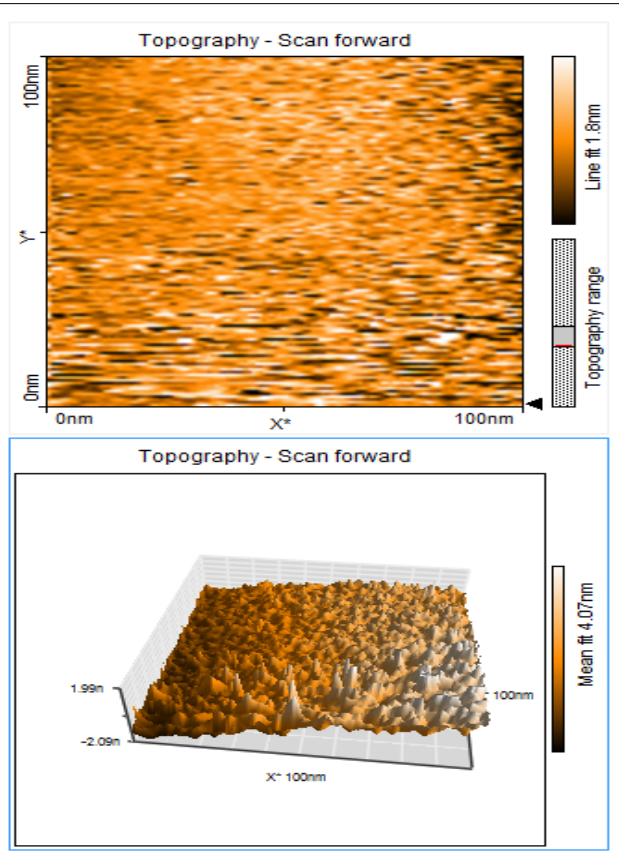

Figure 5: Scanning Tunneling Microscopic image of silver nanoparticles biosynthesized from orange juice. 
Citation: Hungund BS, Dhulappanavar GR, Ayachit NH (2015) Comparative Evaluation of Antibacterial Activity of Silver Nanoparticles Biosynthesized Using Fruit Juices. J Nanomed Nanotechnol 6: 271. doi:10.4172/2157-7439.1000271

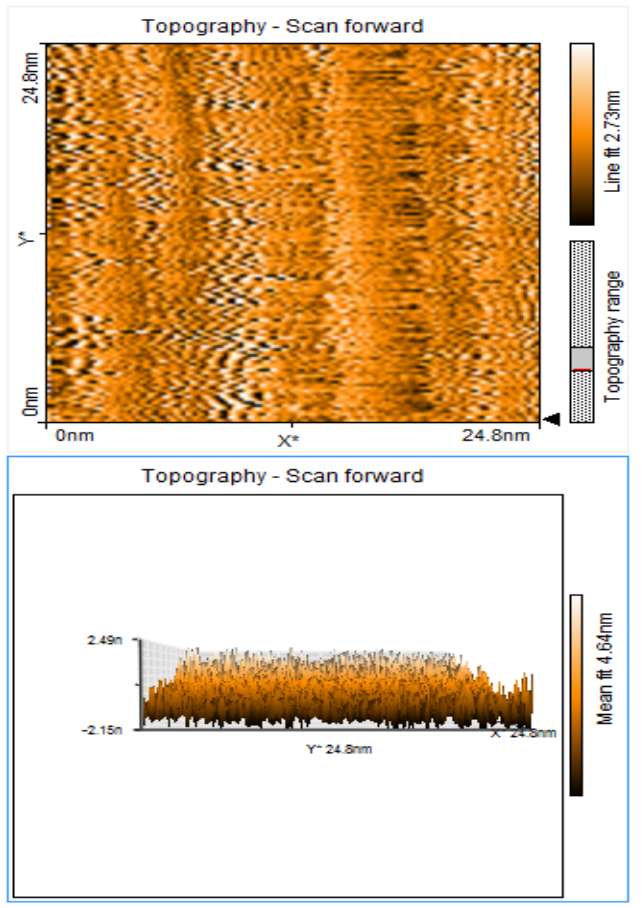

Figure 6: Scanning Tunneling Microscopic image of silver nanoparticles biosynthesized from sweet-lime juice.

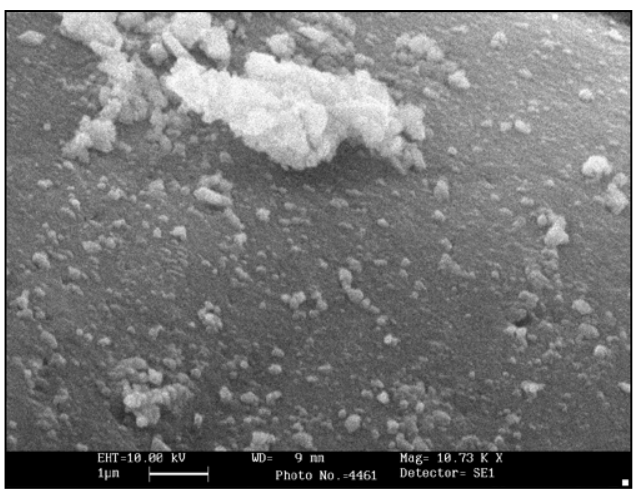

Figure 7: Scanning electron micrograph of silver nanoparticles biosynthesized from lime juice.

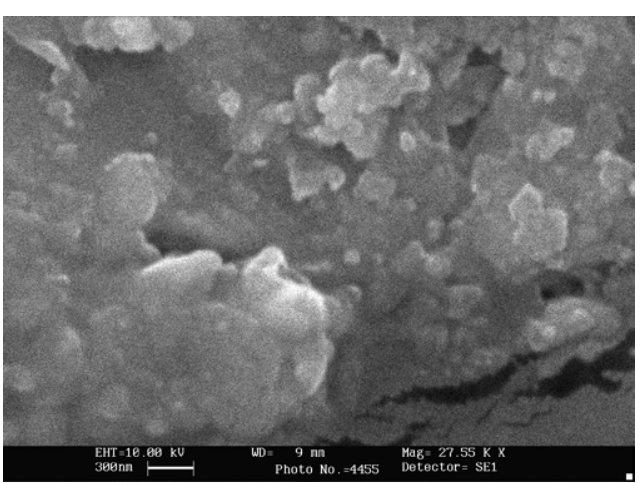

Figure 8: Scanning electron micrograph of silver nanoparticles biosynthesized from orange juice.

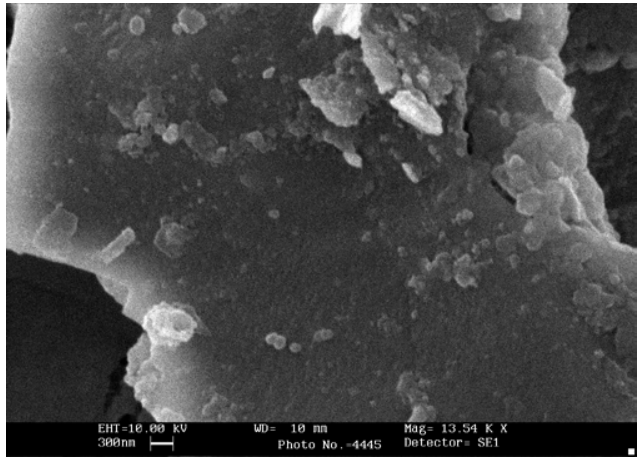

Figure 9: Scanning electron micrograph of silver nanoparticles biosynthesized from sweet-lime juice.

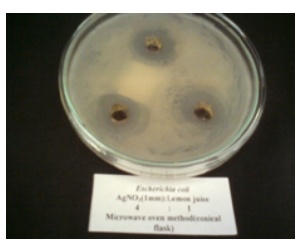

A) Escherichia col

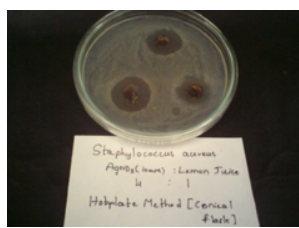

C) Staphylococcus aureus

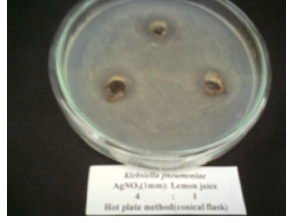

B)Klebsiellapneumoniae

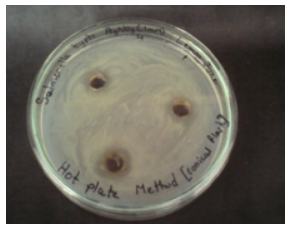

D) Salmonella typhimurium
Figure 10: Comparison of antibacterial activity of silver nanoparticles biosynthesized from lime juice against A) Escherichia coli, B) Klebsiellapneumoniae, C) Staphylococcus aureusand D) Salmonella typhimurium.

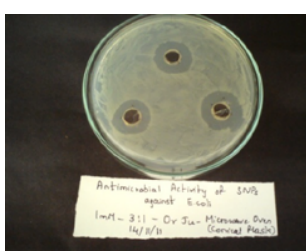

A) Escherichia coli

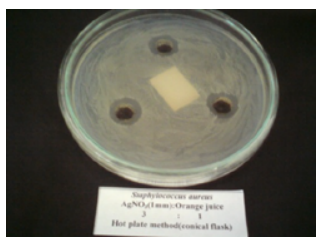

C) Staphylococcus aureus

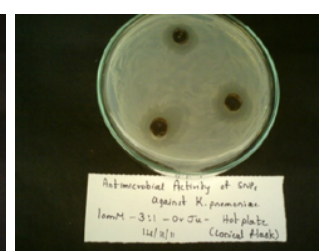

B) Klebsiellapneumonice

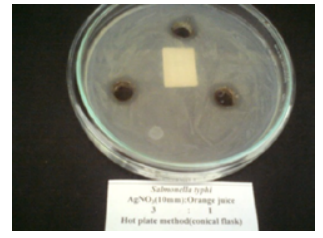

D) Salmonella typhimurium
Figure 11: Comparison of antibacterial activity of silver nanoparticles biosynthesized from orange juice against A) Escherichia coli, B) Klebsiellapneumoniae, C) Staphylococcus aureusand D) Salmonella typhimurium.

organisms: S. aureus and S. typhimurium respectively. (Table 1 and Figure 10-12). Table 1 gives the ZoI of the formed silver nanoparticles against pathogens E.coli, K. pneumoniae, S. aureus and S. typhimurium. Considering the advantage of the microbicidal activities of the silver 


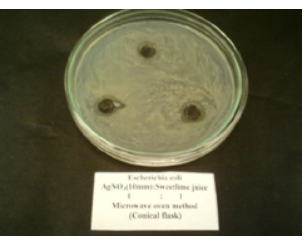

A) Escherichia coli

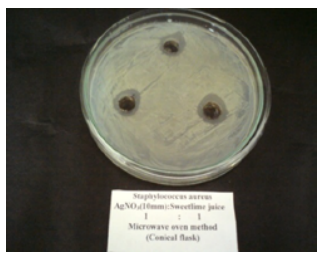

C) Staphylococcus aureu

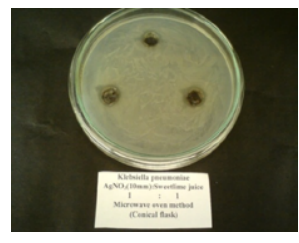

B)Klebsiellapneumoniae

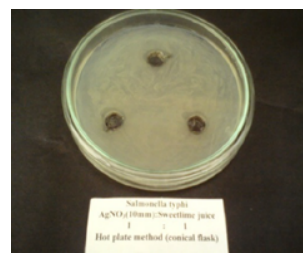

D) Salmonella typhimurium

Figure 12: Comparison of antibacterial activity of silver nanoparticles biosynthesized from sweet-lime juice against A) Escherichia coli, B) Klebsiellapneumoniae, C) Staphylococcus aureusand D) Salmonella typhimurium.

\begin{tabular}{|l|c|c|c|}
\hline Microorganism & Lime juice & Orange juice & Sweet-lime juice \\
\hline Escherichia coli & 7 & 8 & 6 \\
\hline Klebsiella pneumoniae & 6 & 8 & 5 \\
\hline Staphylococcus aureus & 5 & 5 & 4 \\
\hline Salmonella typhimurium & 6 & 6 & 4 \\
\hline
\end{tabular}

Table 1: Zone of inhibition $(\mathrm{mm})$ of silver nanoparticles biosynthesized from fruit juices against test microorganisms.

compounds and the ability to stay as drug without microbial resistance, chemical drugs are slowly taken over by bioorganic nanoparticles. Smaller particles with a larger surface area possess higher antibacterial effects compared to the larger particles [23]. The antibacterial activity of the nanoparticles may be centered on permeability of bacterial cell wall layers or its charges [24]. Studies have shown that nanoparticles may infiltrate the cells causing intracellular loss leading to cell death and this inhibition depends on the concentration of AgNPs [12]. These authors reported the activity of silver nanoparticles was associated with the formation of 'pits' in the cell wall of bacteria, leading to increased membrane permeability resulting into cell death. The mechanism of bactericidal action of silver nanoparticles is still not well understood. The silver ion appears to penetrate through ion channels, denatures ribosomes and suppresses protein expression [25]. AgNPs have considerably minimal microbicidal activity on Gram positive bacteria compared to Gram negative bacteria. This is due to presence of thick peptidoglycan layer of the microorganisms. This is also evident for our studies that, Gram negative bacteria are killed effectively than Gram positive bacteria. Particle size and size of the nanoparticles play important role in characterizing the nanoparticles. These parameters define their in-vivo distribution, biotransformation, toxicity and targeting ability of nanoparticles. One of the limitations for nanoparticles application is their tendency to aggregate because of small size and large surface area. The degree of agglomeration is an important parameter for toxicological studies. Apart from agglomeration, particle size also plays important role in defining the cytotoxic nature of nanoparticles. It was reported earlier by many authors that, smaller the particle sizes more will be the cytotoxic effect of nanoparticles [26]. In our study also, we observed such aggregation of nanoparticles if stored in the aqueous form for long time period. However, such aggregation will lead to loss of properties associated with nano-scale nature of nanoparticles. The present study has not

involved any cytotoxic assessment of the nanoparticles.

\section{Conclusion}

The present approach of biosynthesis of silver nanoparticles used fruit juices as reducing and capping agents. The method is cost effective and environmental friendly. The formed silver nanoparticles were well characterized by UV-Vis spectra, scanning tunneling micrographs and scanning electron micrographs. The antimicrobial activity of these nanoparticles was well demonstrated against both gram positive and gram negative bacteria. The study also confirms that gram positive bacteria are relatively resistant to the bactericidal action than gram negative bacteria. Silver nanoparticles biosynthesized using orange juice were more effective in their antibacterial activity than those from other fruit juices. The approach of use of fruit juices for biosynthesis of nanoparticles is novel and can be adapted to biosynthetic approaches of other metal nanoparticles.

\section{Acknowledgement}

The authors thank Dr. Ashok Shettar, Principal, B.V.Bhoomaraddi college of Engineering and Technology, Hubballi for research support and encouragement.

\section{References}

1. Shiraishi Y, Toshima N (2000) Oxidation of ethylene catalyzed by colloidal dispersions of poly (sodium acrylate)-protected silver nanoclusters. Colloids and Surf. A: Physicochemical and Engineering Aspects 169: 59-66.

2. Chang LT, Yen CC (1995) Studies on the preparation and properties of conductive polymers. VIII. Use of heat treatment to prepare metalized films from silver chelate of PVA and PAN. J Appl Polym. Sci 55: 371-374.

3. Shahverdi AR, Fakhimi A, Shahverdi HR, Minaian S (2007) Synthesis and effect of silver nanoparticles on the antibacterial activity of different antibiotics against Staphylococcus aureus and Escherichia coli. Nanomedicine 3: 168171.

4. Baker C, Pradhan A, Pakstis L, Pochan DJ, Shah SI (2005) Synthesis and antibacterial properties of silver nanoparticles. J Nanosci Nanotechnol 5: 244249

5. Shahverdi AR, Mianaeian S, Shahverdi HR, Jamalifar H, Nohi AA (2007) Rapid synthesis of silver nanoparticles using culture supernatants of Enterobacteria: A Novel biological approach. Process Biochem 42: 919-923.

6. Cao Y, Jin R, Mirkin CA (2001) DNA-modified core-shell Ag/Au nanoparticles J Am Chem Soc 123: 7961-7962.

7. Matejka P, Vickova B, Vohlidal J, Pancoska $P$, Baumuruk V (1992) The role of Triton $\mathrm{X}-100$ as an adsorbate and a molecular spacer on the surface of silver colloid: A surface enhanced Raman scattering study. J Phys Chem 96: 1361-1366.

8. Zou Y, Yu SH, Cui XP, Wang CY, Chen ZY (1999) Formation of silver nanowires by a novel solid-liquid phase arc discharge method. Chem Mater 11: 545-546.

9. Husseiny MI, El-Aziz MA, Badr Y, Mahmoud MA (2007) Biosynthesis of gold nanoparticles using Pseudomonas aeruginosa. Spectrochim Acta A Mol Biomo Spectrosc 67: 1003-1006.

10. Sastry M, Ahmad A, Khan MI, Kumar R (2003) Biosynthesis of metal nanoparticles using fungi and actinomycetes. Curr Sci 85: 162-170.

11. Sharma NC, Sahi SV, Nath S, Parsons JG, Gardea-Torresdey JL, et al. (2007) Synthesis of plant-mediated gold nanoparticles and catalytic role of biomatrixembedded nanomaterials. Environ Sci Technol 41: 5137-5142.

12. Sondi I, Salopek-Sondi B (2004) Silver nanoparticles as antimicrobial agent: case study on E. coli as a model for Gram-negative bacteria. J Colloid Interface Sci 275: 177-182.

13. Lampe JW1 (1999) Health effects of vegetables and fruit: assessing mechanisms of action in human experimental studies. Am J Clin Nutr 70 : 475S-490S.

14. Sun YP, Atorngitjawat $P$, Meziani MJ (2001) Preparation of silver nanoparticles via rapid expansion of water in carbon dioxide microemulsion into reductant solution. Langmuir 17: 5707-5710. 
Citation: Hungund BS, Dhulappanavar GR, Ayachit NH (2015) Comparative Evaluation of Antibacterial Activity of Silver Nanoparticles Biosynthesized Using Fruit Juices. J Nanomed Nanotechnol 6: 271. doi:10.4172/2157-7439.1000271

15. Perez C, Pauli M, Bazerque P (1990) Antibiotic assay by agar well diffusion method. Acta Biol Med Exp 15: 113-115.

16. Mehmood A, Murtaza G, Mahmood Bhatti T, Kausar R (2013) Phyto-mediated synthesis of silver nanoparticles from Melia azedarach L. leaf extract: Characterization and antibacterial activity. Arabian Journal of Chemistry.

17. Sastry M, Mayya KS, Bandyopadhyay K (1997) pH dependent changes in the optical properties of carboxylic acid derivatized silver colloidal particles. Colloids Surf A 127: 221-228.

18. Li S, Shen Y, Xie A, Yu X, Qiu L, et al. (2007) Green synthesis of silver nanoparticles using Capsicum annum L. extracts. Green Chem 9: 852-858.

19. Song JY, Kim BS (2009) Rapid biological synthesis of silver nanoparticles using plant leaf extracts. Bioprocess Biosyst Eng 32: 79-84.

20. Garg A, Garg S, Zaneveld LJ, Singla AK (2001) Chemistry and pharmacology of the Citrus bioflavonoid hesperidin. Phytother Res 15: 655-669.

21. Jiang XC, Chen CY, Chen WM, Yu AB (2010) Role of citric acid in the formation of silver nanoplates through a synergistic reduction approach. Langmuir 26 4400-4408.

22. Ahmad A, Mukherjee P, Senapati S, Mandal D, Khan MI, et al. (2003) Extracellular biosynthesis of silver nanoparticles using the fungus Fusarium oxysporum. Colloids Surf B: Biointerfaces 28: 313-318.

23. Panacek A, Kvítek L, Prucek R, Kolar M, Vecerova R, et al. (2006) Silver colloid nanoparticles: synthesis, characterization, and their antibacterial activity. J Phys Chem B 110: 16248-16253.

24. Chamakura K, Perez-Ballestero R, Luo Z, Bashir S, Liu J (2011) Comparison of bactericidal activities of silver nanoparticles with common chemical disinfectants. Colloids Surf B Biointerfaces 84: 88-96.

25. Yamanaka M, Hara K, Kudo J (2005) Bactericidal actions of a silver ion solution on Escherichia coli, studied by energy-filtering transmission electron microscopy and proteomic analysis. Appl Environ Microbiol 71: 7589-7593.

26. Lara HH, Garza-Treviño EN, Ixtepan-Turrent L, Singh DK (2011) Silver nanoparticles are broad-spectrum bactericidal and virucidal compounds. J Nanobiotechnology 9: 30 . 